\title{
Analysis of Stray Current Induced by Cathodic Protection on Steel- Framed Masonry Structures
}

\author{
Y-Y. Wu ${ }^{1}$, P. Lambert ${ }^{*}, 2$, P. Mangat ${ }^{3}$ and F.J. O’Flaherty ${ }^{3}$ \\ ${ }^{I}$ Electro Tech CP, Structural Group, 4972 Highway 209, Accord, NY 12404, USA \\ ${ }^{2}$ Mott MacDonald, Spring Bank House, Altrincham, WA14 IES, UK \\ ${ }^{3}$ Centre for Infrastructure Management, Sheffield Hallam University, Howard Street, Sheffield, S1 1WB, UK
}

\begin{abstract}
Cathodic protection (CP) has been successfully employed to protect steel-framed masonry buildings from corrosion related damage. When a CP system is installed to protect the structural members, other metallic items which are within the fabric of the structure but are not in direct electrical continuity may suffer from stray current interactions, resulting in accelerated corrosion of the discontinuous items. Therefore, these must be considered when $\mathrm{CP}$ systems are designed prior to installation.

This paper presents both experimental and numerical studies into the risk and extent of stray current corrosion in steelframed masonry structures when subject to impressed current cathodic protection. The objective is to allow CP systems to be optimised so that interference is minimised without compromising the technical or cost benefits of this method of corrosion control.
\end{abstract}

Keywords: Corrosion, steel frame, cathodic protection, impressed current, stray current, numerical modelling.

\section{INTRODUCTION}

Cathodic protection (CP), originally proposed by Humphry Davy [1] and subsequently employed widely on buried and submerged structures as well as for reinforced concrete $[2,3]$, has been successfully used to protect steelframed masonry buildings from corrosion for over a decade [4].

While the majority of $\mathrm{CP}$ installations will operate effectively with no side effects, there remains the risk of stray current corrosion which could be induced in discontinuous metalwork associated with steel-framed masonry buildings [4]. It is widely recognised that such buildings contain a variety of metallic elements. In addition to the frame itself, other items include metal window frames, metal drainage pipes as well as metal fixings such as cramps, lintels and wall ties.

Generally, electrical continuity between structural members is rarely a problem since the structural connections are typically bolted or riveted. But elements outside the main structural frame are more likely to be electrically discontinuous. When a CP system is installed to protect the structural members, other items which are within the fabric of the structure but are not in electrical continuity may suffer from stray current interactions, resulting in accelerated corrosion of the discontinuous items. Therefore, these must be considered when $\mathrm{CP}$ systems are designed and before installation.

\footnotetext{
*Address correspondence to this author at the Mott MacDonald, Spring Bank House, Altrincham, WA14 1ES, UK; Tel: +44 (0)161 926 4155; E-mails: paul.lambert@mottmac.com
}

The boundary element method has been widely used to analyse CP systems for offshore and marine structures [5-8]. More recently, the method has been introduced to analyse CP systems for steel-framed masonry structures $[9,10]$. The method has also been employed to model the stray current corrosion of ships and pipelines [11], predict the likelihood of $\mathrm{CP}$ interference on steel structures located in proximity to large cathodically protected chemical storage tanks [12], and analyze the risk of stray current corrosion between ships and steel piles [13].

This paper presents both experimental and numerical studies into the risk and extent of stray current corrosion in steel-framed masonry structures when subject to impressed current CP. The objective is to allow CP systems to be optimised so that interference is minimised without reducing any of the technical or cost benefits associated with the technique.

\section{EXPERIMENTAL PROCEDURE}

The principles and basic components of impressed current cathodic protection (ICCP) systems have been well documented and described elsewhere [14]. Based on these, a representative ICCP system which incorporates two electrically discontinuous steel bars was constructed to analyze the distribution of the protective potential and current as well as the magnitude and effect of stray current.

The main components of the system are a direct current power supply; a titanium oxide ceramic discrete anode; a carbon steel ' $I$ ' section as the cathode with dimensions as shown in Fig. (1). Two steel bars, each $8 \mathrm{~mm}$ diameter $\mathrm{x}$ $200 \mathrm{~mm}$ length employed to represent electrically discontinuous metal items; sandbox fabricated from poly- 


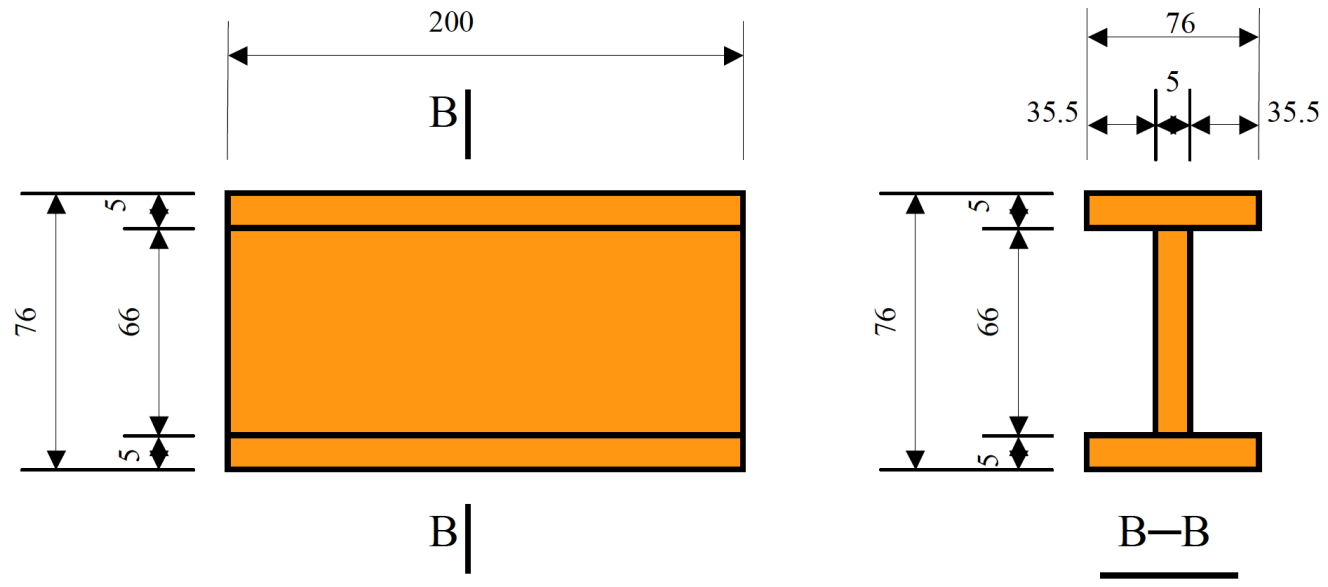

Fig. (1). Steel section (mm).

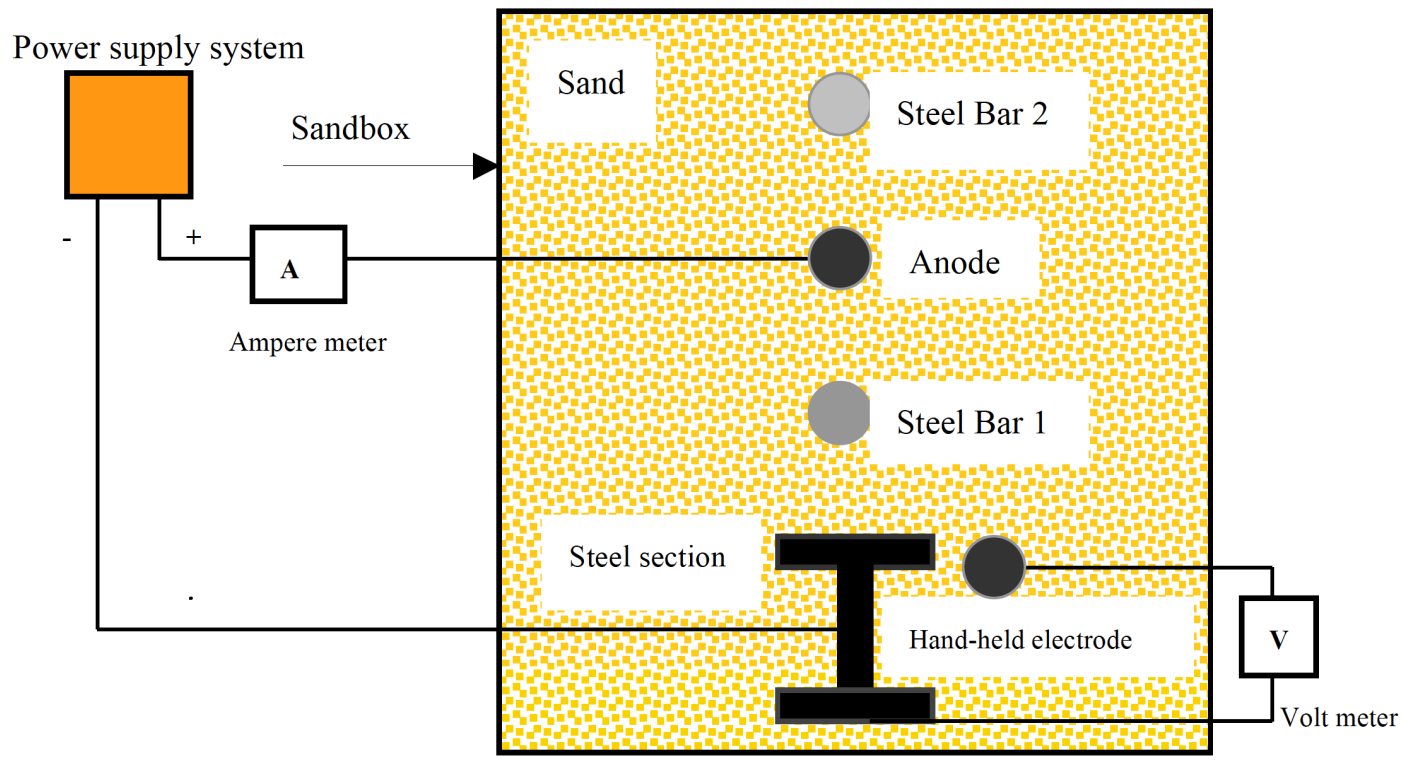

Fig. (2). Schematic representation of test arrangement.

methyl-methacrylate (PMMA) with dimensions of $100 \mathrm{~mm}$ length, $360 \mathrm{~mm}$ width and $560 \mathrm{~mm}$ height (Fig. 2).

Building sand was employed to represent the surrounding masonry. The moisture content of the sand was adjusted to achieve a similar resistivity to masonry within the range 10$50 \mathrm{~K} \Omega . \mathrm{cm}$ as measured by a proprietary resistivity meter. The completed test specimen is shown in Fig. (3). The experimental work was performed at a constant $20^{\circ} \mathrm{C}$ and $60 \%$ Relative Humidity in an environmentally controlled room.

The potential distribution was measured on a grid under a range of test conditions, including various sand resistivities and output currents, by moving a hand-held copper/copper sulphate reference electrode (CSE) over the surface of sand. Potential values obtained in this manner do not represent the actual protective potential values on the surface of the steel section as they incorporate a potential drop or $I R_{\Omega}$.

In order to obtain the value of the $I R_{\Omega}$-free $\mathrm{CP}$ protective potential on the surface of steel, the instant-off potential method is employed, whereby the current is briefly interrupted (turned off) and a value of potential taken immediately afterwards whilst no current is flowing and there is, therefore, no potential drop. The power is then reapplied. As the steel section has a very complex geometry, it is not possible to accurately measure every point on the steel surface. Due to this limitation, only the protective potential at selected points on the top surface of the steel section was measured.

\section{BOUNDARY ELEMENT METHOD}

For a uniform isotropic electrolyte, the flow of current can be shown to obey the following Laplace equation, as represented in Fig. (4) [5-8]:

$k \nabla^{2} E(p)=0 p \in \Omega$

where $E$ is the potential at any point $p(\mathrm{x}, \mathrm{y}, \mathrm{z})$ of the domain

$k$ is the conductivity of the electrolyte

$\Omega$ is the domain under consideration

The problem in cathodic protection is to solve the above Laplace equation subject to the following boundary conditions:

$E=E_{0}$ on $\Gamma 1$ 


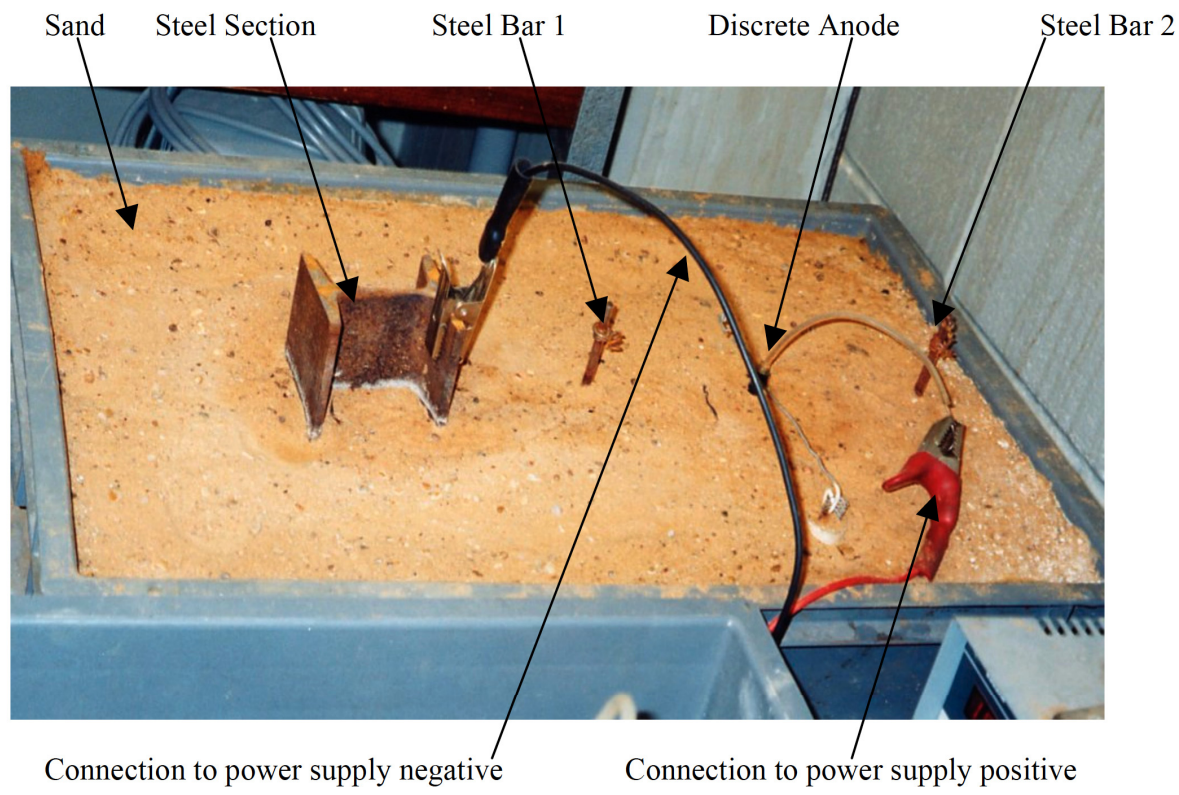

Fig. (3). Test specimen and components.

$i=k \frac{\partial E}{\partial n}=i_{0}$ on $\Gamma 2$

$i_{a}=-f_{a}\left(E_{a}\right)$ on $\Gamma \mathrm{a}$

$i_{c}=-f_{c}\left(E_{c}\right)$ on $\Gamma \mathrm{c}$

where $\Gamma(=\Gamma 1+\Gamma 2+\Gamma \mathrm{a}+\Gamma \mathrm{c})$ is the surface of the electrolyte domain $\Omega, E_{0}$ and $i_{0}$ are the prescribed values of potential and current density respectively.

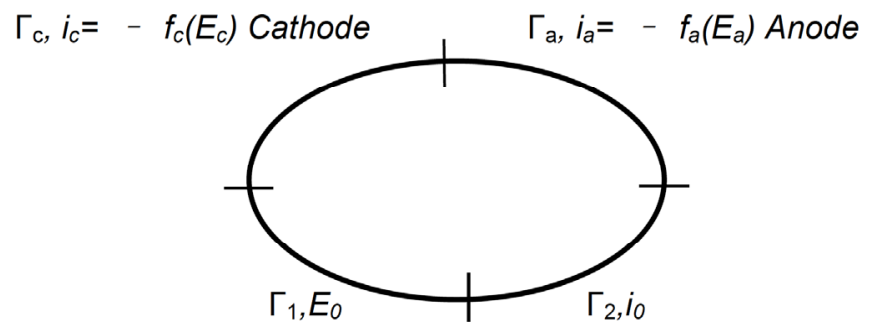

Fig. (4). Boundary conditions for a uniform isotropic electrolyte.

Equations 4 and 5 describe the relationship between the potential $\mathrm{E}$ and current density $\mathrm{i}$ on the anode surface and cathode surface separately, known as the polarization curves, and are experimentally determined. A series of linear algebraic equations are generated which may be written in matrix notation $[15,16]$ :

$H E=G i$

where $H$ and $G$ are the $\left(\begin{array}{lll}n & x & n\end{array}\right)$ square matrices, called the influence matrices, and $E$ and $i$ contains the nodal potential vectors and the nodal normal current density vectors separately. Rearranging equation (6) to get all known values on the right-hand side and then multiplying out, and all unknown values on the left-hand side, gives:

$A X=F$

where $A$ is the coefficient matrix, $X$ is the vector of the unknown values of potential and current density on the boundaries, and $F$ is an independent vector.
For the linear boundary conditions, the above equation can be solved by Gauss Elimination or LU Decomposition. However, in practice the boundary conditions on the anodes and cathodes are represented by the non-linear polarisation curves. Equation 7 is, therefore, solved by an interactive procedure [7, 17]. After all values of the potential and current densities in Equation 7 are solved, the solution of the internal point in the electrolyte domain can be calculated $[15$, $16]$.

\section{RESULTS AND DISCUSSION}

The system was analyzed under the conditions shown in Table 1.

\section{Table 1. Test Conditions}

\begin{tabular}{|c|c|c|c|}
\hline & & Case 1 & Case 2 \\
\hline \multicolumn{2}{|l|}{ Average sand resistivity $(\mathrm{K} \Omega . \mathrm{cm})}$. & 42.0 & 15.0 \\
\hline \multirow[t]{6}{*}{ Axis co-ordinates of anode } & $\mathrm{P} 1$ & $\mathrm{X}=17.8 \mathrm{~cm}$ & $\mathrm{X}=17.8 \mathrm{~cm}$ \\
\hline & & $\mathrm{Y}=43.0 \mathrm{~cm}$ & $\mathrm{Y}=43.0 \mathrm{~cm}$ \\
\hline & & $Z=0.0$ & $Z=0.0$ \\
\hline & $\mathrm{P} 2$ & $\mathrm{X}=17.8 \mathrm{~cm}$ & $\mathrm{X}=17.8 \mathrm{~cm}$ \\
\hline & & $Y=43.0 \mathrm{~cm}$ & $\mathrm{Y}=43.0 \mathrm{~cm}$ \\
\hline & & $\mathrm{Z}=10.0 \mathrm{~cm}$ & $\mathrm{Z}=10.0 \mathrm{~cm}$ \\
\hline \multirow[t]{6}{*}{ Axis co-ordinates of steel bar 1} & $\mathrm{P} 1$ & $\mathrm{X}=17.8 \mathrm{~cm}$ & $X=17.8 \mathrm{~cm}$ \\
\hline & & $\mathrm{Y}=33.0 \mathrm{~cm}$ & $\mathrm{Y}=33.0 \mathrm{~cm}$ \\
\hline & & $\mathrm{Z}=0.0$ & $\mathrm{Z}=0.0$ \\
\hline & $\mathrm{P} 2$ & $\mathrm{X}=17.8 \mathrm{~cm}$ & $\mathrm{X}=17.8 \mathrm{~cm}$ \\
\hline & & $\mathrm{Y}=33.0 \mathrm{~cm}$ & $\mathrm{Y}=33.0 \mathrm{~cm}$ \\
\hline & & $\mathrm{Z}=10.0 \mathrm{~cm}$ & $\mathrm{Z}=10.0 \mathrm{~cm}$ \\
\hline \multirow[t]{6}{*}{ Axis co-ordinates of steel bar 2} & P1 & $\mathrm{X}=17.8 \mathrm{~cm}$ & $\mathrm{X}=17.8 \mathrm{~cm}$ \\
\hline & & $\mathrm{Y}=53.0 \mathrm{~cm}$ & $\mathrm{Y}=53.0 \mathrm{~cm}$ \\
\hline & & $\mathrm{Z}=0.0$ & $\mathrm{Z}=0.0$ \\
\hline & $\mathrm{P} 2$ & $\mathrm{X}=17.8 \mathrm{~cm}$ & $\mathrm{X}=17.8 \mathrm{~cm}$ \\
\hline & & $\mathrm{Y}=53.0 \mathrm{~cm}$ & $\mathrm{Y}=53.0 \mathrm{~cm}$ \\
\hline & & $\mathrm{Z}=10.0 \mathrm{~cm}$ & $Z=10.0 \mathrm{~cm}$ \\
\hline Applied current density $\left(\mathrm{mA} / \mathrm{cm}^{2}\right)$ & & $5 \times 10^{-4}$ & $2.50 \times 10^{-3}$ \\
\hline
\end{tabular}


The locations of the anode and steel bars are the same in both cases. The total boundary element mesh used for the analysis is shown in Fig. (5). For clarity, the boundary element mesh on the surface of the steel section and steel bar is also shown separately in Fig. (6).

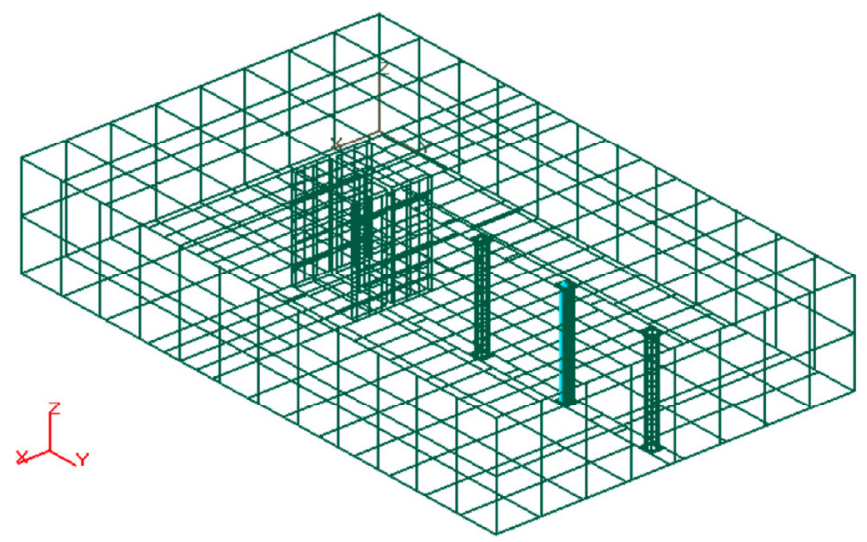

Fig. (5). Schematic representation of the total boundary element mesh on the surface of sandbox.

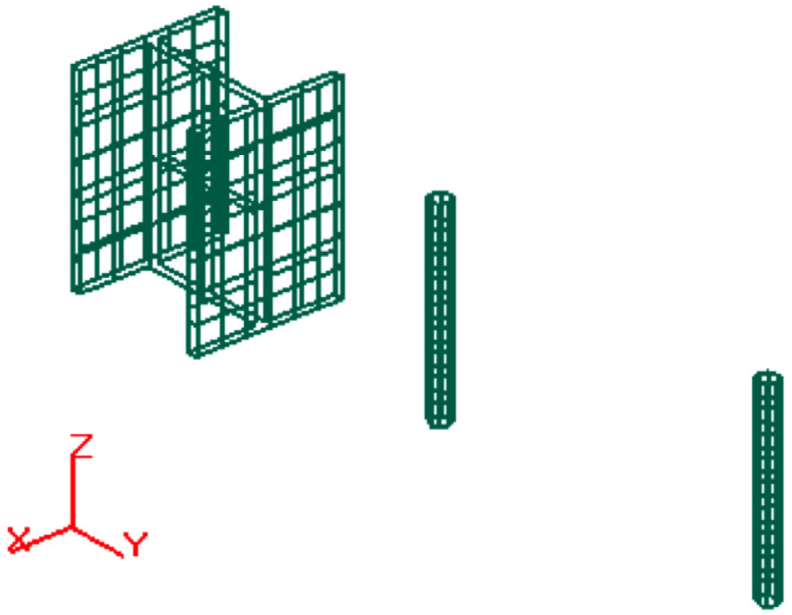

Fig. (6). Schematic representation of the element mesh on the surface of steel section and steel bar.

The results obtained indicate that stray current corrosion cannot be simply identified by analyzing the potential distribution on the surface of the sandbox or steel. However, the study of normal current density distribution on the surface of two steel bars showed clear demarcation between anodic and cathodic areas.

In areas of both bars closest to the anode, the measured current is negative, demonstrating that current is being picked up, consistent with cathodic behaviour. Simultaneously, the current on the areas furthest away from the anode is positive, reflecting a current discharge consistent with anodic behaviour and as a result, corrosion is induced at these areas. Examples of the results demonstrating this effect are shown in Figs. (7-10).

The stray current density on the surface of Steel Bar 1 is higher than on the Steel Bar 2 in both Case 1 and Case 2. This is clearly indicated in Figs. $(\mathbf{7}, \mathbf{8})$ (Case 1) and Figs. (8, 10) (Case 2). Therefore, it is apparent that the effect of stray current corrosion on Steel Bar 1 is greater than that on Steel Bar 2 in the present study.

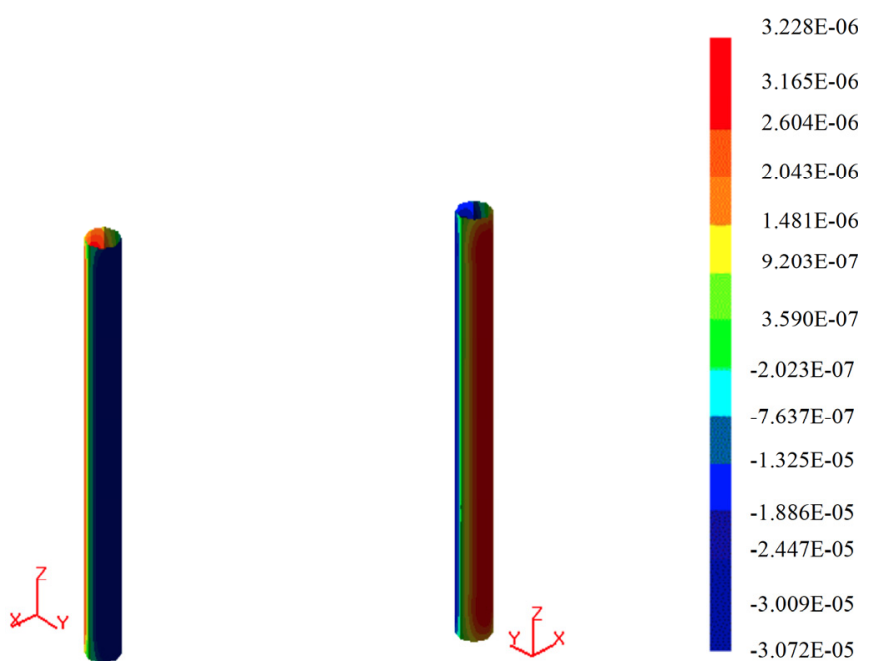

Fig. (7). Normal current distribution on the surface of Steel Bar 1 $\left(\mathrm{mA} / \mathrm{cm}^{2}\right.$, - current in, + current out, Case 1).

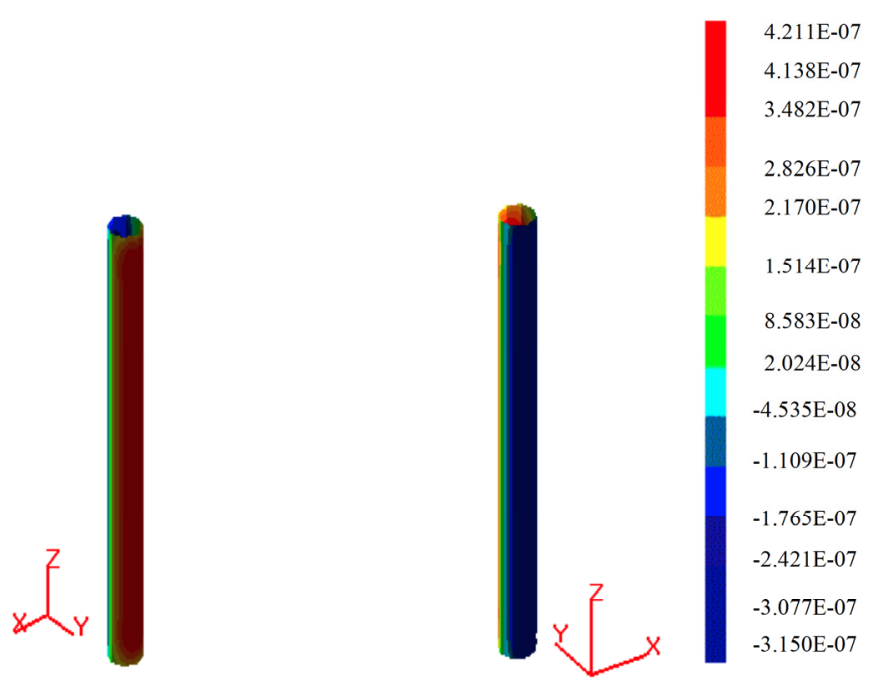

Fig. (8). Normal current distribution on the surface of Steel Bar 2 $\left(\mathrm{mA} / \mathrm{cm}^{2}\right.$, - current in, + current out, Case 1$)$.

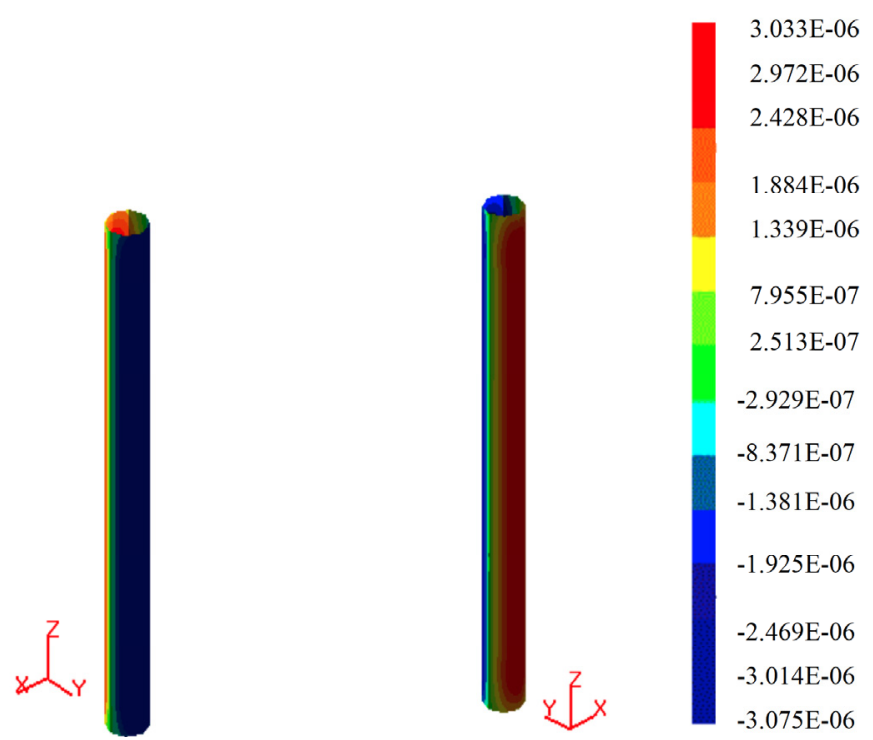

Fig. (9). Normal current distribution on the surface of Steel Bar 1 $\left(\mathrm{mA} / \mathrm{cm}^{2}\right.$, - current in, + current out, Case 2). 


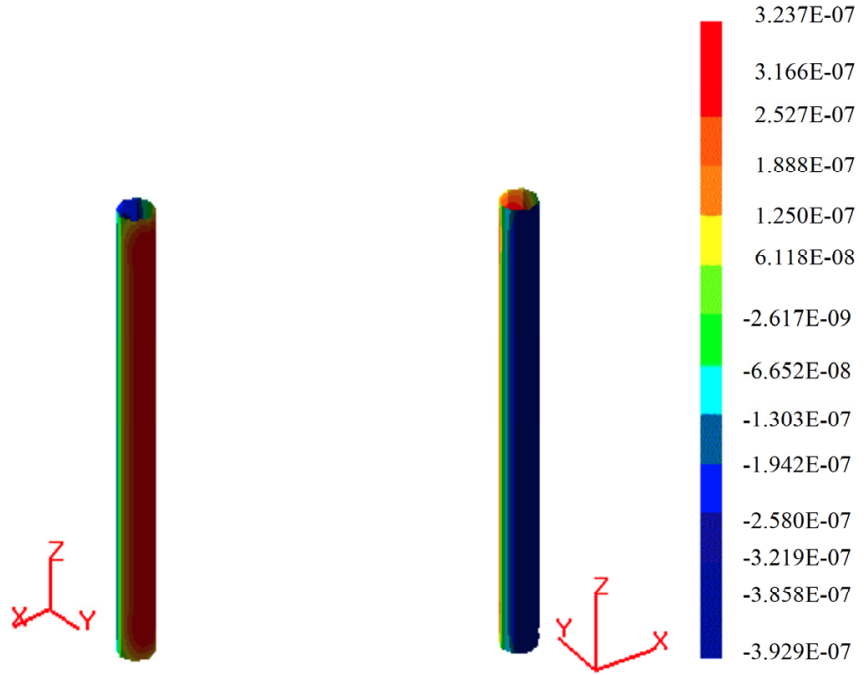

Fig. (10). Normal current distribution on the surface of Steel Bar 2 $\left(\mathrm{mA} / \mathrm{cm}^{2}\right.$, - current in, + current out, Case 2).

This would appear to be because Steel Bar 1 is located directly between the anode and the steel section where the greatest current may be expect to flow. Steel Bar 2, although adjacent to the anode, is not in the direct path between the anode and the steel and as a consequence the extent of current pick-up is greatly reduced.

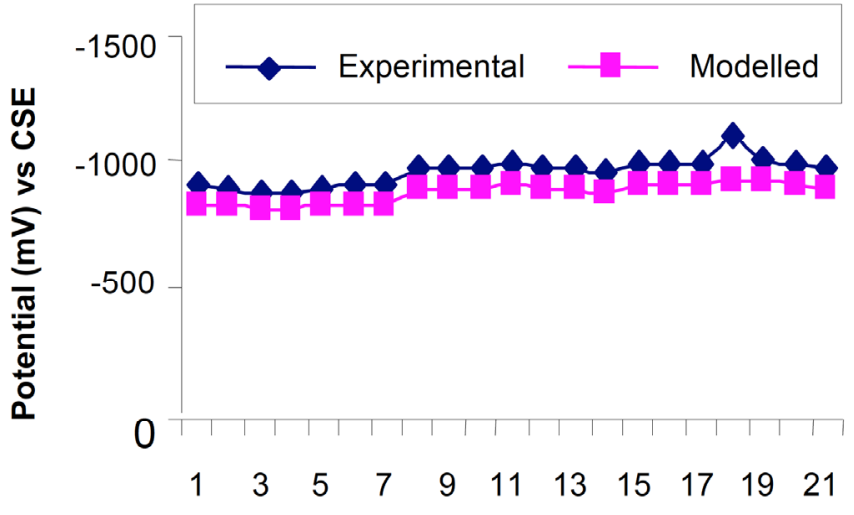

Coordinate points on the free sandbox surface

Fig. (11). Comparison of experimental measurement of potential with boundary element solutions (Case 2).

The boundary element technique can however be used to model stray current corrosion induced by CP interference. It can provide information about the level of interference in terms of current density rather than potential, from which rates of metal loss can be calculated.

Boundary element modelling has therefore been shown to be a useful tool for the analysis of CP interference in steelframed masonry buildings and may be employed to reduce

Table 2. Coordinates of Representative Points on the Free Sandbox Surface

\begin{tabular}{|c|c|c|c|c|c|c|c|}
\hline Coordinates & Point $1(5,10,10)$ & Point $2(10,10,10)$ & Point $3(15,10,10)$ & Point $4(20,10,10)$ & Point $5(25,10,10)$ & Point $6(30,10,10)$ & Point $7(35,10,10)$ \\
\hline & Point $8(5,38,10)$ & & & & & & \\
\hline Coordinates & Point $15(5,48,10)$ & Point $16(10,48,10)$ & Point $17(15,48,10)$ & Point $18(20,48,10)$ & Point $19(25,48,10)$ & & Point $21(35,48,10)$ \\
\hline
\end{tabular}

The results of the boundary element modelling in Case 2 are now compared with the experimental measurements at the representative points as shown in Fig. (11). The coordinates of the points plotted in Fig. (11) are given in Table 2. Whilst they generally follow the same trend, there is a relatively small difference of around $50 \mathrm{mV}$ in the potential values between the boundary element solutions and the experimental data. The reasons for this difference could be associated with the experimental procedure, the modelling or both. For example, inaccurate experimental measurements could result from resistance drops in the cables and equipment or errors in data capture. In the boundary element modelling, possible causes of inaccuracy could include errors in the experimentally obtained polarization curves or inaccurate discretisation of the element mesh. Although there is some difference between the boundary element results and the experimental data, the general level of agreement is sufficiently good to confirm the validity of the modelling approach and to allow the results to be employed for design purposes.

\section{CONCLUSIONS}

The results demonstrate that the potential distribution cannot be used to identify or accurately illustrate the effect of stray current corrosion on electrically discontinuous steel. or remove the risk of stray current corrosion when evaluating or designing ICCP systems for such applications.

\section{ACKNOWLEDGEMENTS}

The authors would like to gratefully acknowledge the financial support of The Royal Society, Mott MacDonald Group Ltd and Sheffield Hallam University.

\section{REFERENCES}

[1] Davy H. On the corrosion of copper sheeting by seawater, and on methods of preventing this effect, and on their application to ships of war and other ships. Proc R Soc 114: 151-246, 1824 and 115: $328-46$

[2] Heuze B. Cathodic protection of steel in prestressed concrete. Maters Perform 1965; 11:57-62

[3] Stratfull R F. Experimental cathodic protection of a bridge deck, Transportation Research Record 500. Transportation Research Board, Washington D C1974, USA.

[4] Atkins C P, Lambert P, Coull Z L. Cathodic protection of steelframed heritage structures. Proceedings of 9th International Conference on Durability Building Materials Components, Australia 2002, 11pp

[5] Gartland P O, Johsen R. COMCAPS-Computer Modelling of Cathodic Protection Systems, NACE. Corrosion'1985; 85: 319.

[6] Adey, R A, Niku, SM, Brebbia, C A and Finnegan, J. Computer Aided Design of Cathodic Protection, Boundary Element Methods VII, Villa Olmo 1985; Lake Como, Italy.

[7] Zamani, N G. Boundary Element Simulation of Cathodic Protection System in Prototype Ship. App Math Comput 1988; 26(2): 118-34 
[8] Adey, RA, Niku, S M (1992) Computational Modelling of Corrosion Using Boundary Element Methods. Computer Model Corr, STP 1154, ASTM, Philadephia, pp.248-63.

[9] Lambert P, Mangat P S, O'Flaherty, F J, Wu, Y.-Y. Cathodic protection of steel framed masonry structures: experimental and numerical studies. Mat Struc 2008; 41: 301-10.

[10] Lambert P, Mangat P S, O'Flaherty, F J, Wu, Y.-Y. Influence of resistivity on current and potential distribution of cathodic protection systems for steel framed masonry structures. Corr Eng Sci Tech 2008; 43(1): 16-22.

[11] Trevelyan, J, Hack, HP. Analysis of Stray Current Corrosion Problems using Boundary Method. Boundary Element Technology IX 1994.
[12] Strong, G E, Adey, R A, Rudas, RS. Computer Prediction of Stray Current Corrosion, Australian Corrosion Conference, Melbourne 1997, Australia.

[13] Adey, R A, Pei Yuan Hang. Computer Simulation as an Aid to Corrosion Control and Reduction, NACE Corrosion' 99, San Antonio, USA.

[14] Broomfield, J P. Corrosion of Steel in Concrete: Understanding, Investigation and Repair 1997, E \& FN SPON.

[15] Brebbia, C A. The Boundary Element Method for Engineers, Pentech Press 1978, London.

[16] Brebbia, C A and Dominguez J. Boundary Elements- An Introductory Course, McGraw-Hill 1989, New York.

[17] Press, W H. Numerical recipe: the art of scientific computing. Cambridge 1992 University Press.

Received: July 12, 2011

(C) Wu et al.; Licensee Bentham Open.

This is an open access article licensed under the terms of the Creative Commons Attribution Non-Commercial License (http://creativecommons.org/licenses/by-nc/ 3.0/) which permits unrestricted, non-commercial use, distribution and reproduction in any medium, provided the work is properly cited. 